\title{
Análise da distribuição e composição profissional dos Núcleos de Apoio à Saúde da Família no Paraná
}

Family Health Support Teams distribution and professional composition in Paraná

Alessandro Rodrigo Pedroso Tomasi', Maria Lucia Frizon Rizzotto²

${ }^{1}$ Mestrando do Programa de PósGraduação em Biociências e Saúde da Universidade Estadual do Oeste do Paraná (UNIOESTE) - Cascavel (PR), Brasil.

arp.tomasi@gmail.com

2 Doutora em Saúde Coletiva pela Universidade Estadual de Campinas (UNICAMP) - Campinas (SP), Brasil.

Professora do Programa de Pós-

Graduação em Biociências e Saúde da Universidade Estadual do Oeste do Paraná

(UNIOESTE) - Cascavel (PR), Brasil.

frizon@terra.com.br
RESUMO: Os Núcleos de Apoio à Saúde da Família (NASFs) se constituem em uma estratégia criada pelo Ministério da Saúde, em 2008, com o objetivo de modificar a lógica hegemônica de prestação do cuidado em saúde. Desde então, o Paraná, como os demais estados, vem progressivamente aderindo a esta política. Neste trabalho analisou-se a composição e a distribuição dos NASFs no estado do Paraná a partir dos dados disponíveis no Cadastro Nacional de Estabelecimentos de Saúde (CNES). A coleta ocorreu de maio a junho de 2012 e observou-se uma heterogeneidade na distribuição e na composição profissional das equipes, que, em grande medida, acompanha a lógica da implantação das equipes de saúde da família no estado.

PALAVRAS-CHAVE: Atenção básica; Serviços de saúde; Planejamento em saúde

ABSTRACT: The Family Health Support Teams (FHST) are a strategy created in 2008 by Brazilian Ministry of Health, attempting to modify the hegemonic thinking in health care. Since then, Paraná State, just as the other States, is progressively using the politics. In this paper has been analyzed the FHST composition and distribution in Paraná, using the data available in National Database Health Services (NDHS). The data were collected in 2012, May and June, and has been possible to notice heterogeneity in distribution and team's composition, which follows the same thinking about family health teams in State.

KEYWORDS: Primary health care; Health services; Health planning 


\section{Introdução}

Desde a sua criação, o Sistema Único de Saúde (SUS) tem enfrentado inúmeros obstáculos para a sua consolidação. Entre eles destacam-se a manutenção do modelo curativo de atenção e a dificuldade em estabelecer uma rede regionalizada de serviços que atenda de forma integral as necessidades de saúde da população. $\mathrm{Na}$ última década, vários programas foram propostos com o objetivo de contribuir para transformar essa realidade, entre eles, o Programa Saúde da Família (PSF), criado em 1994, e mais recentemente, em 2008, os Núcleos de Apoio à Saúde da Família (NASFs), além da própria Política Nacional de Atenção Básica (PNAB), publicada em 2006 e reeditada em 2011.

Já os NASFs se configuram como um serviço que proporciona um suporte especializado com profissionais de determinados núcleos de conhecimento, acionados de acordo com as necessidades da ESF, no sentido de aumentar a resolutividade das ações na atenção básica. Compostos por equipes multiprofissionais, devem atuar de maneira integrada no apoio às ESFs com o intuito de ampliar o escopo e a resolubilidade das açóes da atenção básica. Compartilham as práticas, os saberes e o cuidado em saúde da população de um dado território, atuando diretamente no apoio matricial às equipes da(s) unidade(s) na(s) qual(is) estão vinculados (BRASIL, 2012a).

O apoio matricial é um dispositivo que visa a assegurar a retaguarda assistencial às equipes de referência, além de suporte técnico-pedagógico. Na primeira dimensão, a atuação dos profissionais do NASF se dá por meio de açóes que envolvem diretamente a assistência ao usuário a partir de atendimentos conjuntos com as equipes de referência, sendo estas arranjos que permitem a mudança de foco na atenção individualizada, transferindo-o para as equipes que realizam o acompanhamento longitudinal das famílias/casos sob sua responsabilidade. $\mathrm{Na}$ segunda dimensão, a atuação é no sentido de instituir um processo de educação permanente junto às equipes que recebem o apoio. Essas duas dimensões, a assistencial e a técnico-pedagógica, devem se dar de forma articulada e permanente, constituindo-se em uma nova proposta de organização dos serviços de saúde na atenção básica materializada nos NASFs (BRASIL, 2004; 2009; CAMPOS; DOMITTI, 2007).

Para Cunha e Campos (2011), o apoio matricial deve ocorrer junto às equipes de referência e operar a partir da discussão dos núcleos e campos de saberes, ou seja, profissionais com determinado núcleo de conhecimento realizam o suporte para outros profissionais, com outros núcleos de conhecimento. Campos, Chakour e Santos (1997) afirmam que os conceitos de campo (saberes mais gerais) e núcleo (saberes mais específicos) são importantes para a realização do trabalho matricial, na medida em que ajudam a esclarecer e delimitar as atividades privativas de cada profissional que compõe a equipe de saúde e aquelas que podem ser compartilhadas com outros profissionais.

Esta conformação da atenção pauta-se no fortalecimento do vínculo equipe de saúde/usuário, na medida em que as açôes em saúde são pactuadas entre estes dois atores. Desse diálogo pode-se elaborar o Projeto Terapêutico Singular (PTS), dispositivo utilizado pela equipe de saúde na cogestão e coprodução de sujeitos singulares, desenvolvido de forma conjunta pela equipe e usuário/ família, a partir das potencialidades e recursos disponíveis na localidade e no serviço de saúde. Esta proposta visa a contribuir para superar a lógica vigente no SUS de um sistema hierarquizado, que utiliza mecanismos de referência e contrarreferência, e de centrais de regulação (CAMPOS, 1999; CAMPOS; DOMITTI, 2007; OLIVEIRA, 2010; CUNHA; CAMPOS, 2011).

O Paraná, em 2012, contava com 1.819 ESFs e apenas 68 NASFs implantados, o que significa que grande parte das ESFs existentes no estado estava sem apoio. Conhecer a composição e a distribuição dos NASFs no Paraná foi o objetivo central deste trabalho, cujos resultados apontaram territórios com maior concentração e aqueles com vazios assistenciais. Trata-se de uma pesquisa documental, realizada a partir de dados disponíveis no Cadastro Nacional de Estabelecimentos de Saúde (CNES), coletados durante os meses de maio e junho de 2012.

Os dados foram relativos à quantidade de núcleos em todo o estado do Paraná e em relação à composição profissional das equipes. Das equipes NASFs, os dados 
foram tabulados em planilha eletrônica e a distribuição foi disposta em um mapa. Em relação à composição profissional, foi realizado um mapeamento dos profissionais que compunham as equipes NASF no período da coleta, sendo realizada análise descritiva dos dados.

\section{Criação e funcionamento dos NASFs}

Os NASFs foram criados pela Portaria no $154 / 08$. Em 2011, os núcleos foram incluídos na Política Nacional de Atenção Básica, por meio da Portaria no 2.488/11 e, em 2012, tiveram seus parâmetros de vinculação quantitativos e qualitativos em relação às ESFs alterados, por meio da Portaria no 3.124/12, além da criação da modalidade NASF III (BRASIL, 2008; 2011a; 2012).

Desta forma o NASF tipo I deve ser composto por profissionais que tenham o somatório de carga horária de, no mínimo, 200 horas, sendo as ocupações com carga horária entre $20 \mathrm{~h} /$ semanais e $80 \mathrm{~h} /$ semanais, isoladamente. Os NASF tipo II devem estar vinculados de três a quatro ESFs, com acúmulo de carga horária em $120 \mathrm{~h} /$ semanais e com cada ocupação isoladamente somando de 20 a 40 horas de carga horária semanal. Por fim, o NASF tipo III deve estar vinculado de uma a duas equipes de saúde da família, com o somatório de carga horária dos membros da equipe de, no mínimo, $80 \mathrm{~h} /$ semanais. Isoladamente, as ocupaçóes devem respeitar um encargo semanal de 20 a 40 horas semanais, assim como no NASF tipo II (BRASIL, 2012c).

O NASF não é caracterizado como um serviço de livre acesso à população. Os profissionais desses núcleos podem realizar atendimentos individuais e coletivos, de forma pontual, desde que a demanda seja regulada pela ESF. Além disso, os atendimentos devem ser decididos em conjunto com a equipe de referência e outras redes, como a assistência social e outros recursos da comunidade, como associação de moradores, igrejas e escolas (BRASIL, 2011a).

Concebido dentro de um modelo assistencial que preconiza não somente outra forma de atenção à saúde, mas a reorganização de todo o processo de trabalho, além de beneficiar o usuário - na medida em que coloca este como o objeto de intervenção, diferentemente do que se realiza no modelo hegemônico que utiliza como objeto de intervenção essencialmente a doença -, beneficia também os profissionais de saúde que atuam nos serviços. Isso porque coloca o profissional como mais um dos atores na construção da intervenção e não como o único ou principal. Nesse diálogo/ interação entre trabalhador e usuário ambos contribuem e assumem responsabilidades na condução do processo terapêutico e na própria forma de intervir no processo saúde-doença.

O processo de criação de NASF é de iniciativa do gestor municipal. Devem ser identificadas as principais demandas de saúde da região na qual o(s) núcleo(s) será(ão) implantado(s) e considerada a disponibilidade de profissionais na região/município. $\mathrm{O}$ projeto de implantação deve ser aprovado pelo Conselho Municipal de Saúde e ser enviado à Secretaria Estadual de Saúde que, no prazo máximo de 30 dias, encaminha para análise da Comissão Intergestora Bipartite (CIB). Em não havendo resposta dentro do prazo estipulado, o município pode encaminhar a solicitação de implantação do NASF diretamente ao Ministério da Saúde (BRASIL, 2008).

Para aprovação do projeto devem constar as informaçôes de infraestrutura disponível para o funcionamento e os profissionais que comporão os núcleos, bem como a forma de contratação e as atividades que seráo realizadas. Nos anexos da Portaria nº154/2008 existem modelos que podem ser seguidos pelos gestores, na elaboração do projeto para criação do serviço.

\section{Distribuição dos NASFs no Paraná}

O Paraná, um dos três estados que compóem a região Sul do Brasil, possui 399 municípios e população de 10.444.526 habitantes (IBGE, 2010). Está subdividido em 22 Regionais de Saúde (RS) compondo quatro Macrorregióes de Saúde (MR): leste, oeste, noroeste e norte (PARANÁ, 2012).

Entre maio e junho de 2012, período da coleta de dados, estavam cadastrados no CNES 1.533 serviços de atenção básica, compostos por centros de saúde, unidades básicas de saúde, postos de saúde, núcleo integrado de saúde, centro de apoio à saúde da família, centro 
social e pronto atendimento municipal. Nestes serviços, atuavam 2.019 equipes sendo $1.819 \mathrm{ESF}$, considerando todas as modalidades de ESF propostas pelo Ministério da Saúde na Portaria no 703/11, 132 equipes que atuam especificamente em atenção domiciliar, consultório de rua, multiprofissional de atenção primária, ribeirinha e/ ou indígena e 68 equipes NASF.

Segundo dados recentes da Secretaria Estadual de Saúde (PARANÁ, 2013), a cobertura do estado com a estratégia saúde da família é de $54,5 \%$. No entanto, apenas $45 \%$ dos municípios alcançam $90 \%$ ou mais de cobertura com esta estratégia. Em geral são municípios de pequeno porte, ou seja, aqueles em que uma ou duas ESF fazem a cobertura de $100 \%$ da população. Isto significa que uma grande parte da população do Estado não está coberta com a estratégia saúde da família e menos ainda com NASFs, já que até o momento do estudo a implantação destes está vinculada a existência de ESF. De acordo com dados do CNES em junho de 2012, dos 399 municípios do estado apenas 31 (7,7\%) possuía NASF implantado. Considerando a organização administrativa da saúde no estado do Paraná, por meio de regionais de saúde, dentre as 22 regionais existentes, sete $(31,8 \%)$ não possuíam nenhum NASF

Figura 1. Número de NASF no Paraná por tipo e regional de saúde. PARANÁ, 2012

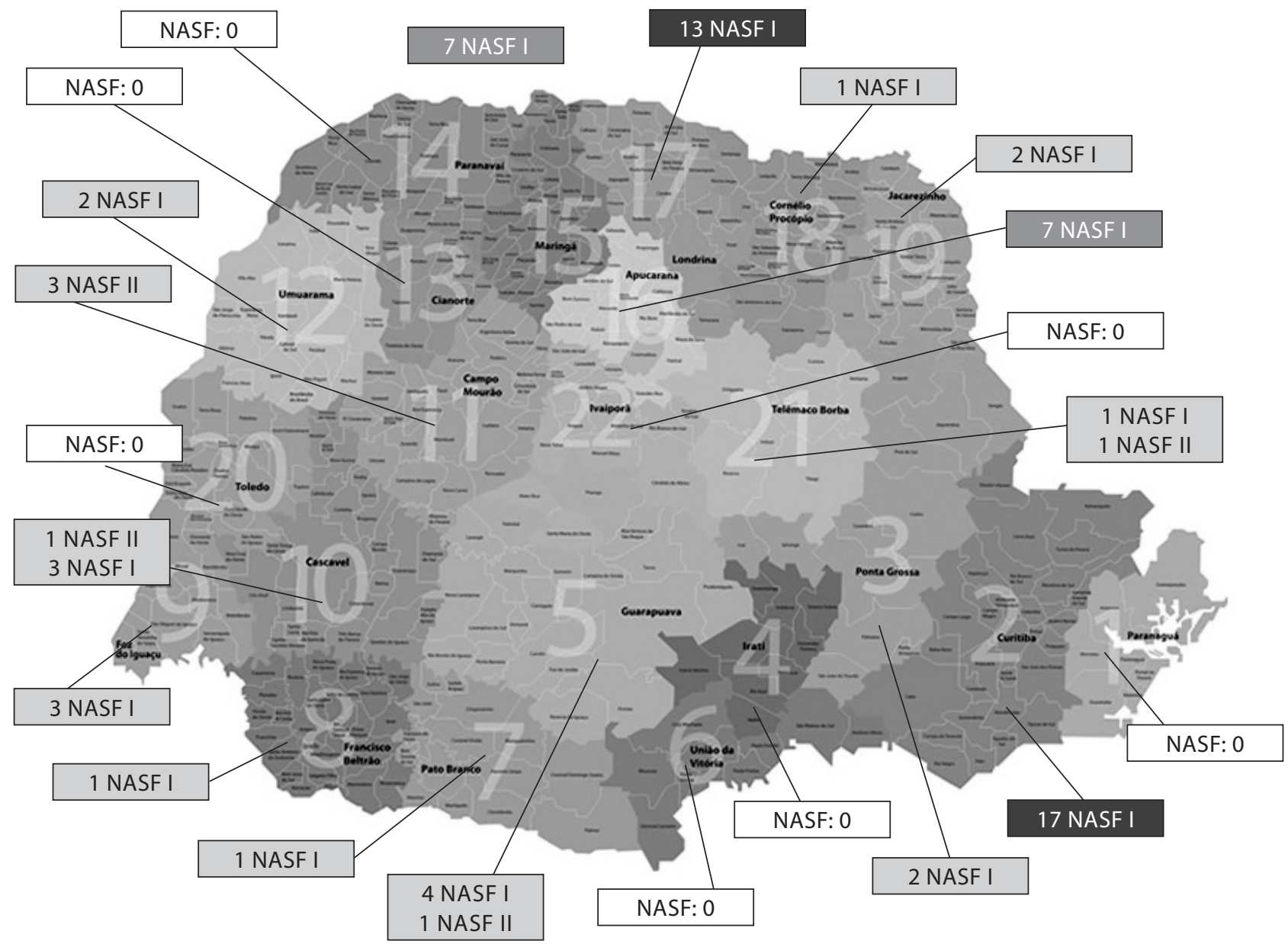

Fonte: CNES, 2012 
implantado nos municípios de sua área de abrangência, $11(50 \%)$ apresentaram entre um e cinco NASF, duas $(9,1 \%)$ possuíam entre seis e 10 NASF e, em outras duas regionais $(9,1 \%)$ havia mais de 10 NASF implantado em diferentes municípios de sua área de abrangência (Figura 1).

Conforme se observa na Figura 1 os NASFs estão mais concentrados nas macrorregióes norte e leste do estado, ou seja, nas regionais de Curitiba (2a), Maringá (15), Apucarana (16a) e Londrina (17a). Isso evidencia uma heterogeneidade no âmbito do estado no que se refere ao esforço em provocar mudanças no modelo assistencial e, consequentemente, na transformação da atenção básica em ordenadora da rede de atenção à saúde.

Quanto aos tipos de NASF, apenas nas seguintes regionais de saúde haviam NASF do tipo II: 5ª (Guarapuava), 10 (Cascavel), 11ª (Campo Mourão), 18 a (Cornélio Procópio) e 21a (Telêmaco Borba), ou seja, núcleos com equipes menores, com, no mínimo, três profissionais. Nas demais regionais, os NASFs eram do tipo I, com, no mínimo, cinco profissionais compondo a equipe.

As razóes para as disparidades macrorregionais observadas podem ser inúmeras, tanto de ordem local/ micro como mais gerais. Entre as razóes locais que podem contribuir para acelerar ou retardar o processo de mudança, destacam-se a gestão municipal, o preparo da equipe técnica, o exercício do controle social, o tamanho e a localização dos municípios, o desenvolvimento econômico e social, a distância/proximidade com centros urbanos, o acúmulo histórico e a própria trajetória do setor saúde do município.

Além desses possíveis fatores internos aos municípios, neste trabalho interessa destacar um aspecto mais geral, que é o papel do governo estadual no planejamento e na organização da assistência no território estadual. Aqui, assumem papel de destaque as regionais de saúde, que se constituem na representação do governo estadual em nível regional, com a responsabilidade de auxiliar, apoiar e induzir a adoção de políticas de saúde pelos municípios e monitorar a sua execução/ implementação.

A questão que permanece em aberto é o peso que cada um desses fatores pode ter na organização e na oferta de serviços de saúde nas diferentes regióes do estado. Mas, pelo poder técnico e político que possui, não se pode desresponsabilizar as regionais de saúde por certo fracasso observado em algumas regióes do estado no que diz respeito à cobertura da população com ESF e à implantação de NASFS vinculados a estas equipes, que têm como objetivo aumentar a resolutividade da atenção básica e provocar mudanças do modelo de atenção à saúde.

Para Molini-Avejonas, Mendes e Amato (2010), os NASFs podem ajudar a ampliar o escopo de açóes das ESF, ampliar as práticas integrativas e complementares, e oferecer a melhor tecnologia para a prevenção/ tratamento de grande parte das doenças crônicas. Os mesmos autores sinalizam que a criação do NASF teve, além de outros, o objetivo de fortalecer a atenção básica como porta de entrada do SUS, diminuindo a procura direta por serviços de especialidades.

Os NASFs podem também contribuir com a operacionalização da legislação que regulamenta a atenção básica, tornando este nível de atenção mais resolutivo e ajudando a consolidar o SUS, pois a manutenção do modelo tradicional, ambulatorial, fragiliza o nível primário de atenção. Apesar de que a implantação de NASFs, sem a devida atenção para os pressupostos que orientam essa proposta, pode apenas aumentar a demanda por serviços especializados, fazendo deles um mecanismo de acesso a um atendimento especializado.

\section{Composição das equipes dos NASFs no estado do Paraná}

Nas 68 equipes do estado, em junho de 2012, atuavam 384 profissionais, sendo 87 (22,65\%) fisioterapeutas, 67 (17,44\%) psicólogos, 62 (16,14\%) nutricionistas, 54 (14,84\%) educadores físicos, 43 (11,19\%) farmacêuticos, $30(7,81 \%)$ assistentes sociais, $15(3,9 \%)$ fonoaudiólogos, 10 (2,6\%) ginecologistas, 9 (2,34\%) pediatras, $3(0,79 \%)$ terapeutas ocupacionais, $2(0,52 \%)$ psiquiatras e $2(0,52 \%)$ clínicos gerais.

Ao se comparar os profissionais que podem compor as equipes NASF, indicados na Portaria Ministerial no $2.488 / 11$, com os profissionais que compunham as equipes no Paraná, observou-se que das 19 ocupaçóes 
que podem atuar nos núcleos, 12 estão contempladas. Não se encontrou, entre as equipes, médico acupunturista e médico homeopata.

Ainda de acordo com a Portaria no 2.488/11, o gestor municipal é quem determina a composição dos núcleos, com base nas necessidades locais e na disponibilidade de profissionais. É possível afirmar que, na composição das equipes dos NASFs do Paraná, privilegiou-se o segundo critério - a disponibilidade de profissionais no mercado -, pois, em municípios com vários núcleos, a composição das equipes é idêntica em todos eles, ou seja, não foram levadas em consideração as necessidades locais de saúde.

Exemplo de composição de equipes a partir da 'oferta de profissionais' pode ser evidenciado com os fisioterapeutas e terapeutas ocupacionais. De acordo com o Conselho Federal de Fisioterapia e Terapia Ocupacional (COFFITO), no Brasil, existem 166.265 fisioterapeutas e apenas 14.182 terapeutas ocupacionais. Como mostrado acima, 22,65\% dos profissionais que compõem as equipes dos NASFs no Paraná são fisioterapeutas e apenas $0,79 \%$ são terapeutas ocupacionais. Especificamente no estado, outra explicação para a diferença substancial entre estes profissionais é o número de instituiçôes de ensino que ofertam estes cursos. Em relação às faculdades de Fisioterapia, o Paraná possui atualmente 28 escolas e apenas 1 faculdade de terapia ocupacional (CREFITO 8, s/d).

Formiga e Ribeiro (2012) ressaltam que a inserção do fisioterapeuta nos NASFs é uma primeira aproximação desse profissional com a atenção básica, já que a formação profissional está mais direcionada para as práticas de reabilitação, no nível terciário de atenção, e, em geral, em serviços de natureza privada. A formação é um fator que pode dificultar a operacionalização do trabalho nos NASFs, exigindo um preparo prévio dos profissionais para que, de fato, se operem mudanças nas práticas assistenciais.

No caso da terapia ocupacional, anteriormente ao NASF, este profissional era incluído no SUS por meio das equipes dos Centros de Atenção Psicossociais (CAPS), um serviço de especialidade, desenvolvendo procedimentos mais individualizados (ROCHA; PAIVA; OLIVEIRA, 2012).
$\mathrm{O}$ argumento da baixa oferta de profissionais não pode ser aplicado a outros profissionais, como, por exemplo, aos médicos pediatras. Segundo declaraçóes do presidente do Conselho Regional de Medicina de São Paulo (CREMESP), não há falta de pediatras, mas uma má distribuição destes especialistas. Complementando, o presidente da Sociedade Brasileira de Pediatria (SBP) afirma que a rede pública de saúde náo proporciona incentivos à permanência destes profissionais, principalmente em face dos baixos salários (MIRANDA, 2011).

Recentemente, o Conselho Federal de Medicina (CFM) divulgou um boletim com os resultados da pesquisa demográfica médica no Brasil, apontando a pediatria como a especialidade mais procurada para formação (CFM, 2013).

Em relação ao Paraná, Bonamigo (2011) concluiu que não há falta de médicos, e sim, a má distribuição destes profissionais, que, por melhores condiçôes de trabalho e salário, optam, na maioria das vezes, por permanecerem nos grandes centros ou próximos destes.

No intuito de solucionar a questão da falta de profissionais de saúde em regióes mais carentes (principalmente, a questão de médicos e enfermeiros), em 2001, o Ministério da Saúde publicou o Decreto no 3475/01, implementando o Programa de Interiorização do Trabalho em Saúde. No texto legal são preconizados esforços no sentido de ampliar a cobertura de serviços do SUS, principalmente na atenção básica, além de este se constituir como mais uma tentativa de lidar com a atençấo básica como ordenadora da rede de serviços e, ainda, como uma forma de fortalecer as açóes do PSF em regióes carentes de profissionais (BRASIL, 2001).

Paim (2004) afirma que, mesmo com este programa, a questão da assistência à saúde não sofreu grandes alteraçôes, embora considere esta ação como um passo importante para a consolidação do SUS. Recentemente, em 2011, o Ministério da Saúde publicou a Portaria no 2.087/11, instituindo o Programa de Valorização do Profissional da Atenção Básica. Este programa tem como objetivo central criar cursos de especialização em saúde da família e melhorar as condiçóes de trabalho para médicos, enfermeiros e dentistas, visando à valorização e 
ao aperfeiçoamento destes profissionais para atuação no contexto da atenção básica (BRASIL, 2011b).

A quantidade de nutricionistas nos NASFs do Paraná pode ser explicada, em parte, pela inclusão, na agenda de prioridades do governo federal, a partir de 1999, da implantação de uma política que abordasse os problemas nutricionais do País. Naquela oportunidade foi elaborada a Política Nacional de Alimentação e Nutrição (PNAN) (BARROS; TARTAGLIA, 2003). Em 2012, o Ministério da Saúde reeditou a PNAN, já levando em consideração a existência dos NASFs.

O texto da política indica nove diretrizes de ação neste campo: organização da atenção nutricional; promoção da alimentaçâo adequada e saudável; vigilância alimentar e nutricional; gestão das ações de alimentação e nutrição; participação e controle social; qualificação da força de trabalho; controle e regulaçáo dos alimentos; pesquisa, inovação e conhecimento em alimentação e nutrição; e cooperação e articulação para a segurança alimentar e nutricional (BRASIL, 2012b).

A política indica que as açôes de alimentação e nutrição devem ocorrer no âmbito da atenção básica, mas considera a importância da articulação com os demais níveis de atenção do sistema (BRASIL, 2012b). Desta forma, é possível relacionar a quantidade de nutricionistas nos NASFs com as prioridades da agenda governamental, no que se refere a esta temática em específico. Ainda, a diretriz de qualificação da força de trabalho em saúde indica ações de educação permanente, papel fundamental a ser desenvolvido pelos profissionais dos NASFs em suas açóes com a equipe de referência.

Vale ressaltar, ainda, que a implantação de ações na área de alimentação e nutrição garante incentivos financeiros do governo federal, conforme previsto no texto da PNAN (BRASIL, 2012b).

No caso do psicólogo, Böing e Cepaldi (2010) afirmam que este profissional é incluído no SUS via serviços que prestam atendimentos especializados. Apontam também, neste estudo, que o próprio apoio matricial, da forma como vem ocorrendo, pode ser caracterizado como um serviço de especialidade, devido à organização do processo de trabalho das equipes.

No caderno de diretrizes do NASF, a descrição das açôes sinaliza a atuação de cada profissional em determinadas áreas específicas. Desta forma, os profissionais da área de saúde mental, psicólogos e médicos psiquiatras, por exemplo, são os responsáveis por executar açóes de matriciamento em saúde mental, fisioterapeutas atuam mais voltados à reabilitação e farmacêuticos, na assistência farmacêutica.

Em relação aos profissionais médicos homeopatas e médicos acupunturistas, uma explicação para o fato de nenhum destes ser incorporados às equipes NASF no estado pode ser no sentido de que ainda há resistência, tanto da população quanto do serviço público, em introduzir práticas de medicina alternativa e tradicional chinesa nos serviços de atenção básica.

\section{Considerações finais}

Os NASFs, dispositivos que podem contribuir para modificar as formas de se fazer saúde, vêm ganhando certo espaço no cenário da saúde no Paraná. No entanto, ainda há desigualdade na sua distribuição e composição profissional, com privilégio para os centros urbanos. Este ponto pode estar indicando manutenção de práticas hegemônicas, na medida em que se aumenta a quantidade de profissionais especialistas nos serviços de atenção básica.

Assim, atribui-se a heterogeneidade de distribuição ao planejamento tanto no nível macro quanto no micro/local, o que acompanha, de certa forma, a lógica hegemônica da saúde ainda vigente no estado: maior concentração de equipes NASF nos grandes centros urbanos, ou em regióes próximas a estes.

Neste sentido, observa-se que a implantação de núcleos nos diferentes municípios das regionais provavelmente não vem ocorrendo no sentido de alterar as práticas em saúde, mas sim, no interesse em aumentar a quantidade de recursos financeiros que são destinados aos municípios.

Por outro lado, a implantação de NASFs pelas gestôes municipais pode sinalizar um esforço em gerar mudanças visando a aumentar os níveis de saúde da população, tendo em vista que os núcleos possuem sua concepção a partir de um referencial distinto do modelo hegemônico de fazer saúde. No entanto, aparentemente, há questôes não pendentes em relação ao planejamento 
em saúde, papel exercido tanto pelas gestóes municipais quanto pelas regionais de saúde. Neste ponto, consideramos que ainda há questôes que precisam necessariamente ser debatidas, no sentido de não tornar os NASFs mais uma fonte de arrecadação de recursos financeiros, e sim, uma ferramenta que pode contribuir concretamente para a mudança dos modos de se fazer saúde.

É certo que apenas a implantação de NASFs não é garantia de melhoria nos níveis de saúde da população, uma vez que se sabe que os fatores determinantes da saúde passam por questóes de acesso aos bens e serviços, trabalho, renda, educação e segurança, além de outros.

Da mesma forma, observa-se que a questão da composição profissional dos núcleos segue, aparentemente, a oferta dos profissionais nos municípios, sem necessariamente a observância das necessidades de saúde das regiôes nas quais os NASFs foram implantados. Este ponto é importante, pois apenas a realocação ou a contratação de profissionais disponíveis no mercado não garante, necessariamente, $\mathrm{o}$ atendimento das necessidades de saúde da população.

Considera-se, da mesma forma, que seria necessária a ampliaçáo dos debates sobre o 'como' vem se fazendo saúde naquelas localidades, a partir do aprofundamento de discussões sobre campo e núcleo de conhecimentos, reorganização do processo de trabalho em saúde, a alteração da lógica hegemônica, de forma a construir novas práticas em saúde, efetivamente resolutivas.

\section{Referências}

BARROS, M. S. C.; TARTAGLIA, J. C. A política de alimentação e nutrição do Brasil: breve histórico, avaliação e perspectivas. Alimentação e Nutrição. Araraquara, v. 14, n. 1, p. 109-121, 2003. Disponível em: $\quad$ <http://serv-bib.fcfar.unesp.br/seer/index.php/alimentos/ article/viewFile/847/726>. Acesso em 17 abr. 2013.

BÖING, E.; CREPALDI, M. A. O psicólogo na atenção básica uma incursão pelas políticas de saúde brasileiras. Psicologia Ciência e Profissão. Brasília, v. 30, n. 3, p. 634-649, 2010. Disponível em: <http://pepsic.bvsalud.org/scielo.php?script=sci_arttext\&pi$d=$ S1414-98932010000300014>. Acesso em 18 abr. 2013.

BONAMIGO,T.P. Excesso de médicos na região sul do Brasil. Revista da AMRIGS. Porto Alegre, v. 55, n. 2, 2011. Disponível em: <http:// www.amrigs.com.br/revista/55-02/016-PG_160-163_802_excesso\%20de\%20medicos....pdf>. Acesso em 15 abr. 2013.

Presidência da República. Casa Civil. Subchefia para assuntos jurídicos. Decreto no 3.475 de 05 de fevereiro de 2001. Institui o Programa de Interiorização do Trabalho em Saúde. 2001. Disponível em: <http://www.planalto.gov.br/ccivil_03/decreto/2001/ D3745.htm>. Acesso em 17 abr. 2013.

Ministério da Saúde. Secretaria-Executiva. Núcleo Técnico da Política Nacional de Humanização. Humanizasus: equipe de referência e apoio matricial. Série B Textos Básicos de Saúde. Brasília, 16p., 2004. Disponível em: <http://bvsms.saude.gov.br/bvs/ publicacoes/equipe_referencia.pdf>. Acesso em 03 jul. 2012.

Ministério da Saúde. Secretaria de Assistência à Saúde. Departamento de Atenção Básica. Diretrizes do NASF. Série A.
Normas e Manuais Técnicos. Cadernos de Atenção Básica n. 27. Brasília, 2009, 160p. Disponível em: <http://bvsms.saude.gov.br/ bvs/publicacoes/caderno_atencao_basica_diretrizes_nasf.pdf>. Acesso em 23 jan. 2013.

Ministério da Saúde. Gabinete do Ministro. Portaria $n^{\circ}$ 2.488 de 21 de outubro de 2011. Brasília, 2011a. Disponível em: <http://bvsms.saude.gov.br/bvs/saudelegis/gm/2011/prt2488_ 21_10_2011.html>. Acesso em 17 jan. 2013.

Ministério da Saúde. Gabinete do Ministro. Portaria interministerial no 2.087 de 10 de setembro de 2011. Brasília, 2011b. Disponível em: <http://bvsms.saude.gov.br/bvs/saudelegis/ gm/2011/pri2087_01_09_2011.html>. Acesso em 1 jun. 2013.

Ministério da Saúde. Secretaria de Atenção à Saúde. Departamento de Atenção Básica. Autoavaliação para a Melhoria do Acesso e da Qualidade da Atenção Básica: AMAQ/Ministério da Saúde. Secretaria de Atenção à Saúde. Departamento de Atenção Básica. Brasília, Ministério da Saúde, 2012a, 134p. série B - Textos básicos de saúde. Disponível em: <http://acessopmf.blogspot.com. br/2012/03/autoavaliacao-para-melhoria-do-acesso-e.html>. Acesso em 18 ago. 2012.

Ministério da Saúde. Secretaria de Atenção à Saúde. Departamento de Atenção Básica. Política Nacional de Alimentação e Nutrição. Brasília, 2012b, 84p. Disponível em: <http://189.28.128.100/nutricao/docs/geral/pnan2011.pdf>. Acesso em 23 jan. 2013.

Portaria GM no 154 de 24 de janeiro de 2008. Brasília, 2008. 
Disponível em: <http://189.28.128.100/dab/docs/legislacao/portaria154_04_03_08_re.pdf>. Acesso em 25 jan. 2013.

Portaria n 3.124 de 28 de dezembro de 2012. Brasília, 2012c. Disponível em: <http://bvsms.saude.gov.br/bvs/saudelegis/gm./ 2012/prt3124_28_12_2012.html>. Acesso em 15 dez. 2013.

CAMPOS, G. W. S. Equipes de referência e apoio especializado matricial: um ensaio sobre a reorganização do trabalho em saúde. Ciência e Saúde Coletiva, Rio de Janeiro, v. 4, n. 2, p. 393-403, 1999 Disponível em: <http://www.scielo.br/pdf/csc/v4n2/7121.pdf>. Acesso em 05 jul. 2012.

Saúde pública e saúde coletiva: campo e núcleo de saberes e práticas. Ciência e Saúde Coletiva. Rio de Janeiro, v. 5, n. 2, p. 219-230. 2000. Disponível em: <http://www.gastaowagner. com.br/index.php/component/docman/cat_view/1-artigos?ltemid=>. Acesso em 17 ago. 2012

CAMPOS, G. W. S.; CHAKOUR, M.; SANTOS, R. C. Análise crítica sobre especialidades médicas e estratégias para integrá-las ao Sistema Único de Saúde (SUS). Cadernos de Saúde Pública, Rio de Janeiro, v. 13, n. 1, p. 141-144, 1997. Disponível em: <http:// www.gastaowagner.com.br/index.php/component/docman/ cat_view/1-artigos?start=20>. Acesso em 17 ago. 2012.

CAMPOS, G. W. S.; DOMITTI, A. C. Apoio matricial e equipe de referência: uma metodologia para gestão do trabalho interdisciplinar em saúde. Cadernos de Saúde Pública, Rio de Janeiro, v. 23, n. 2, p. 399-407, fev, 2007. Disponível em: <http://www.scielosp.org/pdf/ csp/v23n2/16.pdf>. Acesso em 05 jul. 2012.

CONSELHO FEDERAL DE MEDICINA (CFM). Sete especialidades concentram mais da metade dos médicos brasileiros. 2013. Disponível em: <http://portal.cfm.org.br/index.php?option=com_content\&view=article\&id=23589: sete-especialidades-concentram-maisda-metade-dos-medicos-brasileiros\&catid=3:portal >. Acesso em 15 abr. 2013.

COSTA, L. R. et al. Distribuição de fisioterapeutas entre estabelecimentos públicos e privados nos diferentes níveis de complexidade de atenção à saúde. Revista Brasileira de Fisioterapia. São Carlos, v. 16, n. 5, 2012. Disponível em: <http://www.scielo.br/ scielo.php?pid=S1413-35552012000500002\&script=sci_arttext\&tlng=pt>. Acesso em 15 abr. 2013.

CREFITO 8. Instituições de ensino de fisioterapia e terapia ocupacional. s/d. Disponível em: <http://www.crefito8.org.br/site/ index.php>. Acesso em 15 abr. 2013.

CUNHA, G. T.; CAMPOS, G. W. S. Apoio Matricial e Atenção Primária em Saúde. Saúde e Sociedade. São Paulo, v. 20, n. 4, p. 961-
970, 2011. Disponível em: <http://www.scielo.br/scielo.php?pi$d=$ S0104-12902011000400013\&script=sci_arttext $>$. Acesso em 20 ago. 2012.

FORMIGA, N. F. B., RIBEIRO, K. S. Q. S. Inserção do fisioterapeuta na atenção básica: uma analogia entre experiências acadêmicas e a proposta dos Núcleos de Apoio à Saúde da Família (NASF). Revista Brasileira de Ciências da Saúde, João Pessoa, v. 16, n. 2, p. 113-122, 2012. Disponível em: <http://www.biblionline.ufpb.br/ojs2/index.php/rbcs/article/view/10639/7300>. Acesso em 15 abr. 2013.

INSTITUTO BRASILEIRO DE GEOGRAFIA E ESTATÍSTICA (IBGE). Censo Demográfico 2010. Disponível em: <http://www.ibge.gov.br/ estadosat/perfil.php?sigla=pr>. Acesso em 17 jan. 2013.

MIRANDA, G. Censo indica que 55\% dos médicos são especialistas. Folha de São Paulo, São Paulo, 2 dez. 2011. Disponível em: <http://www.sbp.com.br/show_item2.cfm?id_categoria=52\&id_ detalhe=4061\&tipo_detalhe=S>. Acesso em 15 abr. 2013.

MOLINI-AVEJONAS, D. R.; MENDES, V. L. S.; AMATO, C. A. H. FOnoaudiologia e Núcleos de Apoio à Saúde da Família: conceitos e referências. Revista da Sociedade Brasileira de Fonoaudiologia, São Paulo, v. 15, n. 4, p. 465-474, 2010

OLIVEIRA, G. N. O Projeto Terapêutico Singular. In: CAMPOS, G. W. S.; GUERRERO, A. V. P. (orgs.). Manual de práticas de atenção básica saúde ampliada e compartilhada. São Paulo: Hucitec, 2010.

PAIM, J. S. Atenção à saúde no Brasil. In: BRASIL. Ministério da Saúde. Saúde no Brasil: contribuição para a agenda de prioridades de pesquisa.. 306p. 2004. Disponível em: <http://iah.iec.pa.gov.br/ iah/fulltext/pc/monografias/ms/saudenobrasil/snbcapp2004.pdf\#page=15>. Acesso em 17 abr. 2013. (Textos Básicos de Saúde, Série B).

PARANÁ. REUNIÃO ORDINÁRIA DA COMISSÃO INTERGESTORES BIPARTITE, 5. 2012, Curitiba. Disponível em: <http://www.sesa.pr. gov.br/arquivos/File/CIB/ATA/ATA_5_RO_23_08_2012.pdf>. Ata eletrônica. Acesso em 17 jan. 2013.

Secretaria de Estado da Saúde do Paraná. Plano Estadual de Saúde. Paraná - 2012-2015. Curitiba, 2013. Disponível em: $<$ http://www.saude.pr.gov.br/arquivos/File/plano_estadual_saude_1104.pdf>. Acesso em 14 jun. 2013.

ROCHA, E. F.; PAIVA, L. F. A.; OLIVEIRA, R. H. Terapia ocupacional na atenção primária à saúde: atribuições, ações e tecnologias. Cadernos de Terapia Ocupacional da UFSCar. São Carlos, v. 20, n. 3, p. 351-361, 2012. Disponível em: <http://www.cadernosdeterapiaocupacional.ufscar.br/index.php/cadernos/article/viewFile/679/393>. Acesso em 18 abr. 2013. 
SILVA, D. J.; DA ROS, M. A. Inserção de profissionais de fisioterapia na equipe de saúde da família e Sistema Único de Saúde: desafios na formação. Ciência e Saúde Coletiva. Rio de Janeiro, v. 12, n. 6, p. 1673-1681, 2007. Disponível em: <http://www.scielosp. org/pdf/csc/v12n6/v12n6a26.pdf>. Acesso em: 15 abr. 2013.

Recebido para publicação em outubro de 2013

Versão definitiva em dezembro de 2013

Suporte financeiro: não houve

Conflito de interesse: inexistente 